\title{
Lutero entre la reforma y la liberación
}

\section{LEONARDO BOFF}

Profesor de te ología sistemática

Pelrópolis, Brasil

\section{Relevancia y delimitación del tema}

El modo de proceder en esta exposición va a ser el siguiente. Partiremos de la teología de la liberación, $y$ ella constituiră el horizonte a partir del cual interrogaremos a Lutero y al movirmiento histórico generado por la Reforma (Wirkunsgeschichte). Desde los intereses, preocupaciones, intuiciones $e$ interrogantes formulados por la teología de la liberación queremos considerar en qué medida Lutero ayuda a comprender nuestra situación de opresión y anima el proce. so de los pobres en busca de su humanización. Tampoco queremos olvi. dar el otro lado de la cuestión: en qué medida Lutero cuestiona a la teología de la liberación, y en qué medida su mensaje y práctica siguen siendo po. siblemente actuales después de casi cinco siglos de haber sido formula. dos.

Tres serán los grandes pasos que daremos; en primer lugar abordare. mos rápidamente lo que propone la teología de la liberación; en segundo lugar, cómo ella se confronta con el protestantismo histórico vivido en América Latina y por último intentaremos formular el posible aporte de Lu. tero a la teología de la liberación.

Reconocemos de antemano la limitación de nuestros conocimientos específicos sobre la inmensa produc. ciōn teológica generada por el fenómeno Lutero. ${ }^{1}$ Pero a pesar de esto. nos atrevemos a expresar algunas opiniones desde nuestro lugar social y eclesial, es decir, desde la América Latina creyente y pobre. y desde una in. serción en una Iglesia comprometida con el caminar de los oprimidos y solidaria con sus anhelos de promoción y liberación.

\section{Una teología desde las clases subalternas: la teo- logía de la liberación}

Mucho se ha escrito ya sobre la teología de la liberación, sus intuiciones, su método, su ubicación eclesial y su inserción en los grupos históricos interesados en la transformación de la sociedad actual.2 Aquí 
queremos enfatizar algunos puntos que nos ayudarán en la confrontación con Lutero y con el protestantismo histórico existente en América Latina.

\section{a) Liberación: un proceso so- cio-histórico concreto}

Cuando hablamos de liberación no la entendemos como una metáfora - en analogía al concepto teológico de redención. Por liberación quere. mos significar en primer lugar un pro. ceso socio-histórico concreto por el cual los pobres, concientizados, organizados y movilizados, buscan su libe. ración mediante la transformación del tipo de sociedad bajo la cual penan y sufren. ${ }^{3}$ La palabra liberaciōn está aquí relacionada con los movimientos liberadores de los pueblos oprimidos desde los tiempos de la colonia $y$, más recientemente, con los procesos revolucionarios ocurridos en México (1911), Bolivia (1952), Guatemala (1952), Cuba (1959 bajo Fidel Castro) y con los grupos guerrilleros del Perú, Colombia, Argentina, Uruguay, Chile y Brasil en los últimos 20 años. ${ }^{4}$

El sujeto histórico de esta liberación lo constituyen las capas popula. res y sus aliados (intelectuales orgánicos, sectores de los estratos medios y otros que optaron por las clases populares). Tales movimientos han tomado conciencia de los niveles de explotación a que están sometidas las gran. des mayorias latinoamericanas $y$ han identificado los mecanismos productores del empobrecimiento de las na. ciones. El subdesarrollo no es prima. riamente un problema técnico ni solamente un problema politico; esta es la otra cara de la moneda del tipo de desarrollo generado por el capitalismo mundial, grandes beneficios para los países metropolitanos o céntricos (Ios antiguos imperios coloniales) y gravisimos males a los paises depen. dientes y periféricos. Más que paises subdesarrollados, somos países mantenidos violentamente en un subde. sarrollo mediante procesos de dominación económica, control político y sometumiento ideológico por parte dé las potencias centrales y hegemó. nicas y de sus alıados dentro de los países latınoamericanos. ${ }^{5}$

A partir de los años 30 en casi to. dos los paises esta conciencia ha producido organizaciones populares, sindicatos, partidos de raigambre popu. lar, asociaciones de acción/reflexión etc., con prácticas sociales alternativas, sea para imponer límites a las estrategias de dominación, sea para propiciar rupturas en el sistema e implantar las semillas de una sociedad más participativa a partir del pueblo organizado. Tales prácticas politicas han obligado a las clases hegemónicas nacionales a conceder más poder social a los movimientos populares; han generado el famoso populismo en Argentina, Brasil, Colombia, Santo Domingo y otros países. A partir de los años 60 con la profundización de las reivindicaciones y las exigencias de una sociedad distinta, se ha provocado la ruptura social y la emergencia de regimenes de seguridad nacional con un inmenso y eficaz aparato represivo, responsable de millares de desaparecidos, torturados, exilados y muertos en las macabras cámaras de tortura. Tal represión no ha ahogado los anhelos de libertad, ni ha destrozado totalmente la movilización liberadora de grupos significativos de la sociedad. Por todo el continente latinoamericano existe una significativa fuerza de resistencia, de oposición a 
la dominación y de gestos liberadores.

\section{b) Cristianos solidarios con la liberación}

La Iglesia latinoamericana ha sido, indiscutiblemente, cómplice con el proceso histórico de dominación; ha participado en el proyecto de colonización que desestructuró las grandes culturas-testimonios (Darcy Ribeiro) hasta el dia de hoy. A pesar de su complicidad, siempre ha habido per. sonas para las cuales el evangelio era la referencia fundamental; $y$, en nombre de él, han protestado, tomado la defensa del indigena y denun. ciado la iniquidad cometida con millones de esclavos negros. Modernamente muchos cristianos han participado, sufrido $y$ entregado sus vidas en los procesos de liberación popular. Han sido jóvenes de la pastoral estudiantil, de la pastoral obrera, cristianos con militancia sindical y partidaria. Después del Vaticano II especialmente grupos significativos de sacerdotes y religiosas han sabido aproximarse al pueblo, han organizado una pastoral comprometida con la jus. ticia de los pobres y han llegado a articularse orgánicamente con movimientos más amplios de movilización popular. Ha habido una evangelizaciōn que desentraña sistemáticamente la dimensión liberadora de la fe. Sectores de los distintos episcopados han asumido, en tiempos de represión, una diaconia evangélica y una función profética, prestando su voz a los que no tienen voz y sufren los duros golpes de la represión. Los episcopados de Brasil y de Chile especial. mente se constituyeron en símbolos de una Iglesia comprometida con la suerte de su pueblo oprimido y en la defensa de los derechos humanos. particularmente de los pobres. Figuras como las de Camilo Torres la pesar de lo discutible de su opción politica) Mons. Helder Cámara, cardenal Silva Henriquez, cardenal Evaristo Paulo Arns, Mons. Angelelli y la dei mărtir de la opción por los poures Mons. Oscar Arnulfo Romero repre. sentan simbolos personales de i.niu Iglesia que se desplaza del centro del poder hacia la periferia. ${ }^{6}$

Los cristianos que han sido perse. guidos, torturados y asesinados por su participación en los movimientos populares de liberación se pueden contar por miles. ${ }^{7}$ Nuestra iglesia lati. noamericana tiene mártires: ellos han optado por una práctica social nacida de la adoración del Dios de los israelitas esclavizados en Egipto y del seguimiento del mártir Jesucristo. Este Dios y este seguimiento los han movido a comprometerse hasta las últimas consecuencias en la denuncia del pecado social y en la promoción del proceso de liberación. Fue significativa, y lo continúa siendo, la presencia de los cristianos en la liberación de $\mathrm{Ni}$ caragua de una de las dictaduras más inicuas de nuestro continente y en la construcción de una sociedad organizada desde los olvidados de la tierra.

\section{c) La fe cristiana como factor de liberación de los opri- midos}

El compromiso de los cristianos con la liberaciōn histórica ha ayudado también a que la le se libere de su cautiverio dentro del bloque histórico hegemónico. Sabemos que toda reli. gión -más allá de su especificidad y salvaguardada su experiencia original- existe en y se articula con la for- 
ma concreta de organización de una sociedad dada. 8 Ella se encuentra atravesada, limitada y orientada por los conflictos que caracterizan dicha sociedad. Nuestra sociedad latinoamericana es compleja; existen varios modos de producción coexistentes, pero todos ellos bajc la hegemonía del modo de producción capitalista dependiente y elitista. La sociedad ca. pitalista, por su naturaleza, es muy desigual (asimétrica) con respecto al acceso a los medios de producción (tierras, bancos, industrias), a la distribución de la capacidad de trabajo (grandes propietarios, profesionales liberales y obreros) y a la participación en los productos finales (ricos, bien situados y pobres). Entre las varias clases se dan intereses muchas veces antagónicos y se establece una lucha permanente por la dirección de la globalidad de la sociedad. La clase que empieza a prevalecer, está intere. sada objetivamente en implantar su hegemonia; es decir, intenta ganar el consenso general. Por todos los medios (incluso mediante la coerción) y especialmente por la persuasión (ideología), elabora estrategias de amplificación, consolidación y profundización de su influencia. Tal clase o bloque de clases hegemónico pretende definir las principales orientaciones, valores, limites y prohibiciones que rigen todas las actividades de la sociedad. En este intento por garantizar su hegemonia, la clase dirigente (o bloque de clases) procura ganar para sus intereses a la lglesia, la lectura de los textos fundadores, la organización del discurso cristiano, de la liturgia y de la práctica pastoral. Asi surgió en América Latina una alianza entre el trono y el altar en la colonia y más tarde un pacto entre la Iglesia $y$ los nuevos dirigentes de las repúbli. cas en detrimento de la liberación del pueblo. De esta forma, la Iglesia puede transformarse en un aparato ideológico del Estado (L. Althusser). Pero la cooptación de la fe cristiana jamás fue completà; siempre quedó viva en muchos cristianos de todos los niveles (obispos, sacerdotes, misioneros y laicos) la "memoria subversiva de Jesüs" y de sus origenes humildes, legada a los anhelos liberadores de los pobres.

Con la participación de cristianos en los procesos de liberación, la fe y el evangelio, empezaron cada vez más a ser releidos desde la óptica de los pobres; la religiosidad popular, sectores importantes de la lglesia institucional, muchos agentes de pastoral (teólogos, pärrocos, catequistas, coordinadores de comunidades) comenzaron a codificar los contenidos de la fe, proyectar una determinada imagen de Jesús y comprender la misiōn de la Iglesia en articulaciōn con las luchas de los pobres. Los pobres hicieron una opción por la Iglesia, antes de que la Iglesia en Puebla (1979) hiciera una opción preferencial por los pobres. Desde su ubicación (lugar social) en medio de los oprimidos, la fe cristianá ha podido mostrar su fuerza de resistencia y su relevancia liberadora. Asi se han creado las condiciones sociales para una práctica de ló liberación con inspiraciōn evangélica y las pre-condiciones màteriales para una teologia de la liberaciōn.

\section{d) Reflexión de los cristlanos desde la práctica de libera- ción.}

A partir de una práctica en medios popoulares desde una perspectiva liberadora muchos cristianos tu- 
vieron inicialmente una experiencia espiritual fuerte: se encontraron con el Señor, como Siervo sufriente, en toda una clase social de explotados. Desde ahi se formuló una articulación entre mistica y política, como se puede ver ejemplarmente en Mons. Pedro Casaldáliga, en Ernesto Carde. nal, en algunos de los poemas de mons. Angelelli y en innumerables cánticos religıosos de los cristianos comprometidos. La santidad es politica y las virtudes son aquellas que se necesitan para la solidaridad, la leal. tad al grupo y la lucha en contra de los mecanismos sociales productores de muerte.

En funciōn de la práctica, estos cristianos harı tenido que apropiarse de una lectura más crítica de la sociedad capitalista, manejar conceptos desenmascaradores de la ideología dominante, captar mejor la conciencia colectiva de las opresiones sociohistóricas, proyectar con cierto perfil el tipo de sociedad que se está buscando y movilizarse para avanzar políticamente. Supuesto el horizonte de la fe-compromiso, se ha incorporado un hábito metodológico: ante todo es necesario analizar la realidad y partir siempre de las prácticas con las cuales el pueblo oprimido enfrenta la dominación y se organiza para su promoción.

Finalmente, a partir de la práctica y del análisis social, los cristianos han procurado reflexionar la fe cristiana y los grandes temas de la agenda teoló. gica. Es importante recalcar este hecho decisivo: no se trata de refle. xionar sobre el tema de la liberación, como se puede reflexionar sobre cualquier otro tema (como el trabajo, la sexualidad, la secularización, etc.), sin modificar la manera de hacer teo. logía. Aquí se trata de pensar la fe desule la práctica de la liberación. desde el corazón de un compromiso iluminado por la fe, solidario con los oprimidos e interesado en transformaciones sociales. Esta ubicación concreta del teólogo exige una mane. ra distinta de pensar y de organizar la reflexión en orden a iluminar la prácti. ca y dejarse cuestionar por ella.

Esta producción tiene como sujeto $^{10}$ a los propios cristianos comprometidos, quienes evidente. mente producen un discurso religioso profético, parenético, ético, litúrgico que, aunque no tiene un rigor teórico según los cánones de la teología crítica, tiene eficacia práctica. Sin em. bargo, se ha creado también una teología que reinvidica para si el título de teología, hecha por teólogos que se han incorporado a los movimientos populares y a las comunidades cristianas de base. Estos deben ser considerados como intelectuales religiosos orgánicamente articulados a los inte. reses liberadores del pueblo pobre; ayudan a producir una visión cristiana coherente con el proceso de libera. ción, una catequesis, una lectura del misterio de Jesüs, de la Iglesia, de los sacramentos, de tal forma que las dimensiones intrinsecamente liberadoras sean explicitadas y entregadas a los cristianos comprometidos en di. cha liberación. En razón de esta prác. tica teológica emerge cada vez más un tipo de teólogo cristiano que combina la inserciōn en medios populares y en la práctica pastoral con el estudio y la enseñanza de la teología, in. corporando en su trabajo una lectu. ra critica de la historia desde la óptica de los pobres y sobre ella construir su elaboración teológica. Más que un productor intelectual, es, a su manera, 
un militante, aliado con el pueblo concientizado."1

\section{e) Intuiciones fundamentales de la teología de la libe- ración}

No se puede hacer teología de la liberación sin una previa opciŏn por los pobres. Esta opción tiene una sig. nificación ética indiscutible; tiene un contenido teológico porque Dios, co. mo Dios de vida, mostró en la historia de la salvación que escucha el clamor de los oprimidos; tiene su raiz en la práctica del Jesús histórico que indiscutiblemente hizo una opción por los más necesitados; es una forma de expresión de amor por los pobres y en contra de su pobreza. Finalmente, encierra una innegable dimensión política porque está a favor del polo más débil de la sociedad, generando no pocas veces tensiones y conflictos con los agentes de la clase dominante. Los pobres, en este contexto, no son vistos como individuos desposeidos, sino como toda una clase de trabajadores explotados y privados de vida y dignidad por causa de un proceso social injusto. La pobreza, como lo analizó Puebla, es denunciada al nivel económico-social como "producto de determinadas situaciones y estructuras económicas, sociales, políticas" (n.30,1207-1208); en una lectura ética es acusada de "situaciōn de injusticia" (n.90,509,562) y finalmente desde una visión típica de la fe es considerada como "pecado social" (n.28,487).

Esta situación objetiva de opresión hace que se descubra la teología del cautiverio en Egipto y su impor. tancia para tomar conciencia de la revelación del Dios de Moisés como de un Dios santo y a la vez comprometi. do con sus hijos sometidos. Desde el cautiverio se elabora una perspectiva de liberación que ilumina el proceso concreto de liberación del pueblo. La categoria del Reino de Dios constituye en la teología de la liberación un eje fundamental.

Como lo recalca pertinentemente la Evangelii Nuntiandi, el reino de Dios es "el absoluto" (n.8) y constitu. ye "la liberación de todo lo que oprime al hombre y es sobre todo la liberación del pecado y del maligno, en la alegria de conocer a Dios y de ser por El conocido, de verlo y de entregarse a El" (n.9). El Reino es más que cada una de las liberaciones concretas, porque engloba todo. Pero no sería concreto ni pleno si no implicara la liberación económica, política y social. Como dice Puebla: "El Reino de Dios pasa por realizaciones históricas, pero no se agota ni se identifica con ellas" (n.193); no se identifica con las liberaciones parciales, pero se identifica en ellas, porque solamente asi se hace histörico (Evangelii Nuntiandi 27).

De importancia fundamental es la apropiación del misterio cristológico en términos de liberación. Jesüs fue un liberador de los pobres, enfermos $y$ pecadores (LC. 4,17-21; Mt 11,4-5); su muerte fue consecuencia de su mensaje y de su práctica que entraron en conflicto con los detentadores del poder religioso y político de su tiem. po; su resurrección representa la utopia de una liberación integral. La Iglesia prolonga la misión de Jesús; se ubica dentro del mundo a partir de las exigencias del submundo; predica a todos los hombres la buena noticia de Jesús su opción por los pobres y los no-hombres. Asume la causa de 
los últimos que es defender y promover una vida minimamente digna, los derechos fundamentales de la persona, particularmente los de las grandes mayorias, como el derecho a los medios necesarios para la vida, a la vi. vienda, a la salud, a la educación. En América Latina la Iglesia se ha empeñado, como ninguna otra institución social, en la defensa de los indigenas, muchos de ellos expulsados de sus tierras o condenados a la extinción; ha afrontado y apoyado la reforma agraria, ya que el latifundio constituye estructuralmente uno de los grandes generadores de la pobreza y marginación de millones de personas.

Sería largo describir todas las reflexiones hechas sobre los distintos aspectos de la fe cristiana como respuesta a la práctica de la liberación; especialmente, la dimensión de celebración y de meditación de las Escrituras, en donde el pueblo sencillo alimenta su esperanza del advenimiento de los bienes del Reino y sacia su hambre de Dios. Lo importante es ver cómo los cristianos se articulan con otros movimientos populares $y$, juntos, intentan configurar su vida desde la iluminación que viene del evangelio y del segúimiento de Jesús. Hay una preocupación constante: cómo el evangelio se inserta en la lucha de los oprimidos por su liberación. El evangelio y Jesús no son frenos, sino motores de compromiso para la construcción de un mundo más semejante a la utopía de Jesucristo. Entonces se percibe este carnino de doble via: por un lado, la práctica de liberación ayuda a releer y a entender las fuentes de la fe, la figura de Jesús y la misión de la Iglesia; por otro, la fe y la tradición de la fe ayudan al compromiso por los pobres contra su pobre- za y por su liberación. Esta mutua íecundación confiere credibilidad a la fe cristiana y constituye su mejor testi. monio en favor de la transcendencia, de Dios y de su revelación.

\section{El protestantismo histórico promotor de la libertad burguesa}

¿Cómo se relacionan las "Iglesias histốricas" protestantes de América Latina (la luterana y presbiteriana de orientación confesional y la metodista y bautista de reavivamiento evangélico) con el proceso popular de liberación de los pobres de América Latina? ${ }^{12}$ Para comprender esta relación es importante ubicar históricamente la penetración del protestantismo en el continente latinoamericano. Su presencia activa y organizada comenzó a partir de la segunda mitad del siglo XIX. Provenía de los países centro. europeos. y nordatlánticos, de aquellos países pioneros, por lo tanto, de la "modernidad" y que deten. tan hasta hoy la hegemonia del proyecto liberal. Al llegar a nuestros paises esas Iglesias histōricas traían los ideales del liberalismo. Estos ideales en su aspecto económico reforzaban la modernización e industrialización en contra de las viejas oligarquias terratenientes; en su dimensión política, levantaban la bandera de la democracia representativa; en su vertiente cultural, defendian la educación para todos y la promoción del individuo y su libertad.

Claramente lo formulaba el misionero presbiteriano Stanley W. Ry. croft: "El cristianismo (evangelio), con su énfasis en el valor del individuo y la libertad del espíritu humano bajo la disciplina de Dios, es el más seguro 
fundamento para la libertad y la de. mocracia que América Latina ansia. " 13

En este sentido, el protestantismo histórico ha querido reproducir en América Latina condiciones semejantes a aquellas de sus paises de origen en el hemisferio norte. Para esto hizo una alianza estructural (no necesariamente con intencionalidad subjetiva, pero si de hecho al interior del juego de las fuerzas sociales) con los sectores más avanzados de la sociedad latinoamericana, influenciados por los ideales de la revolución f́rancesa, del iluminismo, del positivismo e incluso de la masoneria. Se trataba de la burguesia nacional, la pequeña burguesía urbana y comercial. Este proceso ocurrió exactamente en el momento en que se daba la transición de la sociedad latinoamericana tradicional y colonial a la moderna y liberal. Hubo conflictos entre los viejos señores y el nuevo sujeto histórico emergente. La Iglesia católica formaba perte del bloque histórico señorial y colonial. Por ello, la Iglesia católica constituyó un enemigo que debía ser combatido fuertemente por los pro. testantes, no solamente por las diferencias confesionales, sino por su función social conservadora. Para el protestantismo histórico "el catolicismo romano es considerado como la ideología y estructura religiosa de un sistema global, el caduco orden his. pánico señorial implantado en Latino. américa, que debe desaparecer para ceder paso a un nuevo orden de. mocrático, liberal, ilustrado, dinámi$\mathrm{co}$, que el protestantismo ha inspira. do históricamente, y al que la doctrina protestante -el libro abierto, el juicio propio- abre paso $\gamma$ sustenta."14

Efectivamente, el protestantismo es innovador frente al pacto colonial del cristianismo (Iglesia católica romana) con las fuerzas del imperio hispano-portugués. Representa un llamado a una vivencia moderna de la fe en articulación con el espiritu imperante de libertad, de participación democrătica y de actualización del proceso productivo. ${ }^{15}$ En términos religiosos se presenta como "fe viva" en contraposición a la "fe muerta" del catolicismo, una religión de tradiciones y exterioridades. Según Gonzalo Baez Camargo, el Cristo en Latino. américa ha sido el "Cristo silencioso," frente al "Cristo sin candado" del protestantismo. ${ }^{16}$

Por otra parte hay que reconocer que la teología protestante está ligada al sujeto histórico liberal. El liberalismo se convirtió en la ideología del imperialismo dorninador, creador de un centro y de una periferia. Desde mediados del siglo XIX se estableció un neocolonialismo en América Latinà. El protestantismo que vino en el seno de los ideales liberales se transformó en un factor legitimador de este pacto neocolonial. Representaba un avance frente a la tradición colonial sustentada por el trono y el altar; pero no era liberador de la estructura fundamental de dominación. Los señores eran otros, pero el sistema de sometimiento y de marginalización de pueblo, siguió su curso. El cambio social que el protestantismo favorecía era sólo reformista; beneficiaba directamente a los estratos medios y altos, y en muy pequeña medida a las capas populares, de manera indirecta. La transformación religiosa centrada en la conversión del corazón, en una fe viva $y$ en prácticas éticas, a pesar de ser personalistas, repercutian en los estratos modernos de la sociedad. El pueblo 
seguia con su religión popular y con el drama de la opresión social.

Con acierto decía Octavio Paz: "La ideologia liberal y democrática, le. jos de expresar nuestra situación histórica concreta, la ocultaba. La menti. ra política se instaló en nuestros pueblos asi constitucionalmente. El daño moral ha sido incalculable $y$ al. canza a zonas muy profundas de nuestro ser. Nos vemos en la mentiracon naturalidad. Durante más de 100 años hemos sufrido regimenes de fuerza al servicio de las oligarquías feudales, pero que utilizaban el lenguaje de la libertad."17 El protestantis. mo histórico mantiene una relaciōn muy intima con esta ideología liberal.

Con la crisis del proyecto liberal. del capitalismo dependiente y perifé. rico, entró en crisis también la comprensiôn liberal del protestantis. mo en América Latina. ¿Puede ser una fuerza de liberación de los oprimidos? José Miguez Bonino formula de forma muy consicente la siguiente tesis: "El protestantismo sólo podrá su. perar la crisis de identidad y misión si en la medida en que logre recuperar el papel subversivo que desempeñó en el pasado, pero en la situación radicalmente distinta en que hoy nos hallarnos."18 Julio de Santa Ana, exmiembro del Consejo Mundial de igle. sias $y$ actualmente secretario general de CESEP en Sao Paulo, propone la encarnación de la Iglesia y del protes. tantismo dentro del mundo de los pobres para ayudar a una transforma. ción profunda y global, una verdadera liberación de los oprimidos. ${ }^{19} \mathrm{Ru}$ bén Alves distingue la función ideoló. gica que el protestantismo desempeñó frente al liberalismo y su permanente función utópica como memoria de la fuerza liberadora del Evangelio.
En esta perspectiva "católicos y protestantes están descubriéndose comio un sólo cuerpo en función de la esperanza en una América Latina nueva. ${ }^{20}$

En verdad, hay un frente liberador protestante de gran significaciōn en el proceso global de la práctica liberadora y de la reflexión que se construye desde esta práctica. Cabe preguntar ahora en qué medida Lute. ro puede corroborar esta misión.

\section{Lutero: liberador en la Igle- sia, reformador en la so- ciedad}

Debemos plantear la siguiente cuestión: hasta qué punto Lutero tiene una función liberadora en el pro. ceso histórico-social-religioso y hasta qué punto, en su teoría y práctica, propició una interpretación legitimadora de la modernidad que tanta opresión trajo a las grandes mayorías empobrecidas de nuestra historia. Para contestar a esta pregunta sería necesaria una investigación muy detallada sobre el fenómeno Lutero en sí y sobre su incidencia en el conjunto de las fuerzas actuantes en aquel tiempo. Para esto no hay ni tiempo ni espacio en esta breve reflexión. Pero intentaremos esbozar algunas perspectivas (incompletas) que nos puedan ayudar a entender el desafio que los explotados no plantean a todos como iglesias cristianas.

Para reflexionar con cierto sentido hermenéutico necesitamos un marco de referencia aunque sea minimo. Asumo la hipótesis (que no se puede aqui profundizar ni justificar) de que un fenómeno religioso como el de Lu. tero no puede ser analizado solamen- 
te con categorias religiosas. Quien se propone hacer un análisis solamente religioso acaba por no hacer un análisis ni siquiera religioso. Esto es asi porque el factor religioso (así como la cultura, las ideologías, los valores) ja. más se estructura solo, sino siempre en articulación con la historia concre. ta y las estructuras económicopolíticas de una sociedad.

Aparte de su carácter especifico. cada factor tiene su indice de incider.cia propia sobre los demás. Pueden darse momentos en que el factor religioso se presenta como dominante, ${ }^{21}$ como parece ser el caso de la Reforma con Lutero. La Reforma es ante todo un fenomeno religioso, pero no solamente religioso; en el campo religioso se revelaron todos los niveles de conflicto que atravesaban la sociedad y la conciencia europea. Con razón decía Henri Hauser: "La Reforma del siglo XVI tuvo el doble carácter de revolución social y revolución religiosa. Las clases populares no se sublevaron sólo contra la corrupción del dogma y los abusos del clero. También lo hicieron contra la miseriay la injusticia. En la Biblia no buscaron únicamente la doctrina de la salvación por la gracia, sino también la prueba de la igualdad original de todos los hombres."22

La cuestión de las causas de la Re. forma es extramadamente comple. $\mathrm{ja}^{23}$ y nadie se atrevería a reducirla a unos pocos factores. Pero lo que po. demos decir con seguridad es que los reformadores, especialmente Lutero. respondieron a los grandes anhelos de su tiempo, marcado por profundas transformaciones por el descubrimiento de nuevos continentes, la colonización, la invención de la impren. ta, la introducción de nuevos sistemas financieros, la emergencia del huma. nismo y especialmente el grito de toda la cristiandad por reformas profun. das en la cabeza y en los miembros de la Iglesia. Con respecto al campo especifico (religioso) dentro del cual se movía, Lutero operó un inmenso proceso liberador. El será para siempre una referencia necesaria a todos los que buscan la libertad y sa. ben luchar y sufrir por ella. Con razón considera Hegel la Reforma luterana como una Hauptrevolution (una re. volución fundamental), por que con "Lutero empieza la libertad del espiritu," libertad que "no solamente es reconocida, sino plenamente exigida."24 Esta libertad eș conquistada rompiendo con el cautiverio babilóni. co en que había caído la cristiandad bajjo lá hegemonía de Roma. Para identificar. mejor el significado liberador de Lutero dentro del campo religioso y desde ahi en los demás campos de la realidad es importante considerar rápidamente el lugar de la lglesia dentro de la formación feudal y se. ñorial de aquel tiempo.

\section{a) Liberación del cautiverio ba- bilónico de la Iglesia}

En la Europa semifeudal y mercantil del siglo XV y XVI la Iglesia constituyó una pieza fundamental. La sede romana y los obispos, particularmente en Alemania, tenian grandes intereses económicos, políticos. jurídicos y militares. No hay que olvidar que el Papa ejercía gran poder temporal con innumerables pactos y beneficios. En el régimen semifeudaly de la burguesía mercantil se daban relaciones de vasallos y súbditos, de señores y siervos, de colonizadores y colonizados. Más en concreto, para mantener sometido al campesinado, a 
pesar de las frecuentes rebeliones en Bohemia, Suabia, Francia y en otras partes de Europa central, no se utilizaba solamente la coerción armada, sino la persuación religiosa. ${ }^{25}$ La aristocracia feudal y la sociedad burguesa mercantilista elaboraron un pacto con el clero (que también tenía poder secular) de tal forma que la Iglesia se constituyó en la instancia central de la reproducción de la sociedad semifeudal y mercantilista. Esto quiere decir que la Iglesia, en su multifuncionalidad, consagró y solidi. ficó las relaciones del status quo, las cuales eran relaciones de dominación. Esta función social de la Iglesia se ejerció con eficacia mediante muchas formas de obras piadosas, devociones a santos, indulgencias compradas con dinero. Por poner un ejemplo, Lutero desaprobó la acumulación en la Iglesia del castillo de Federico el Prudente, de 17.413 reliquias, cuya veneración mediante pagos permitía obtener 128.000 años de indulgencia. 26 Todo este proceso de interacción entre el sistema dominante y el clero tenía su centro de animación y legitimación última en la Sede Romana y en el papado.

Frente a una situación tal, Lutero, que había pasado por una profunda crisis espiritual junto con un deseo profundo de reforma en su orden reli. giosa y en la iglesia entera, lanzó su grito profético. Se reveló contra lo que êl, con frecuencia, liamaba la "tiranía del Papa." A la justificación por las obras, opuso su justificación por la fe. ${ }^{27}$ Celebró el inaudito des. cubrimiento de la ilimitada misericordia de Dios en Jesucristo crucificado. El hombre no estaba condenado a cumplir leyes ni pretendía conseguir la salvación por sus buenas obras. Por lo tanto, su misión en el mundo no consistía en adaptarse a reproducir las normas, con conciencia además de su incapacidad para poder ha. cerlo plenamente. Con su tesis básica de la justificación por la fe, Lutero introdujo una radical liberación. Lo que con esto quería decir era que el ser humano está libre de todas estas exigencias en orden a estar libre para acoger la gracia y la misericordia como puro don y ofrecimiento gratuito del Padre. Como consecuencia de la gracia y de la pura fe (acto globalizante de toda la existencia, el cual es más que la adhesión intelectual a un códi. go de verdades reveladas), ${ }^{28}$ el ser humano produce obras buenas, porque es bueno produce obras buenas; no es bueno porque produce obras buenas. Esta será una afirmación básica de Lutero ${ }^{29}$ que ya la encontró en el Maestro Eckhart. 30

La justificación por la fe es la expresiôn de una increble libertad interior conquistada por Lutero y trans. formada en bandera de liberación para los demás cristianos. Cuando el 16 de abril de 1521, llamado por Carlos $\checkmark$ a la Dieta de Worms, era invitado a abandonar su proclama, Lutero contestó: " $i N o$ puedo ni quiero retractarme, porque no es bueno ni sincero obrar en contra de la propia concien. cra. Que Dios me ayude! ¡Amén!" Instado por última vez por el oficial quien le dijo: "Deja tu conciencia, hermano Martín. Lo único que no ofrece peligro es la sumisión a la autoridad establecida," Lutero lo rechazó definitivamente. $^{31}$ Lutero no tuvo una deferencia servil a ninguna autoridad como última instancia; última instancia solamente puede ser Dios. Dios es un Soberano insustituible y el Papa sólo su servidor. 
Los textos escritos en junio (EI po. der del Papa) en agosto (lamada a la nobleza cristiana de la nación alemana), en octubre (Cautividad babilónica de la Iglesia) y noviembre de 1520 (a libertad del hombre cristiano) revelan una inne. gable aura de liberación. Lo repeti. mos, evidentemente, la tematización era religiosa, pero su efeclo era tam. bién social, político y económico, porque la Iglesia estaba presente en todas estas instancias como la institu. ción básica de coordinación, hege. monización y reproducción del siste. ma imperante.

En la obra El papado de Roma definió la intuición fundamienta! de la eclesiología protestante. La Iglesia visible (corpus christianorum) es puramente humana y no puede identificarse con el cuerpo místico de Cristo. La Iglesia de Cristo es como el Reino que ésta dentro de nosotros, es invisible, es espiritual $e$ interior.

En el escrito de gran virulencia contra el clero y el Papa Llamada a la nobleza cristiana de la nación alemana, denunció los tres muros de los romanistas que impedian la libertad de los cristianos: (1) la superioridad del estado religioso sobre el civil geistlicher Stand-weltlicher Stand) mediante el cual el Papa pretendía dominar a todos. El poder en la Iglesia es únicamente espiritual, una función de servicio y permanece mientras realiza el servicio; fuera de esta inserción diaconal, permanece o vuelve a ser laico. "El carácter indeleble son palabras y leyes inventadas por los hombres." "32 Asi defiende Lutero la vigencia permanente del sacerdocio universal de todos los laicos. El otro muro (2) era el derecho que el Papa se arrogaba de interpretar sólo él las
Escrituras. Lutero que dominaba maravillosamente los textos sagrados (su traducción de la Biblias, genial en la corrección y sencilla en el estilo, conoció 84 ediciones en su tiempo y 253 después de su muerte) afirmó el acceso individual al texto, la ilumina. ción del Espiritu en su interpretación. rompiendo asi el monopolio de la le. gitimidad de interpretación y abrien. do camino para el libre examen. Por fin el tercer muro (3) era la pretensión del Papa de poder convocar y reconocer únicamente él un concilio. En base a textos escrituristicos y testimonios de la tradición, Lutero reivindicó el derecho de los príncipes a convocar un concilio y a forzar una reforma en la Iglesia, incluso "para enseñar al Papa que él es un hombre y no Dios al cual debe estar sometido." 33

En la Cautividad babilónica de la Iglesia denunció las formas en que el cuerpo sacerdotal se habia apode. rado de los sacramentos mediante los cuales mantenia sometidos a todos los cristianos. "Todos ellos fueron reducidos a un mísero cautiverio por lacuria romana. La Iglesia fue privada de toda su libertad." 34 Asumió y defen. dió tres sacramentos como tales, el bautismo, la penitencia y el pan; los demás eran ritos eclesiásticos en función de la vida y de la organización de la comunidad, que tenían legitimidad como construcciones religiosas humanas, pero no como expresión de la voluntad divina. Para Lutero el sacramento era también Evangelium. es decir, la concreción de la palabra de la promesa. Sin el elemento sacra. mental la promesa se quedaba nuda promissio. Pero el sacramento jamás es puro signo, sino un signo que contiene la promesa; por eso, segūn Lutero, no es el sacramento (signo) el que 
comunica salvación, sino la fe en el sacramento (que contiene la prome. 5a). ${ }^{35}$

Con respecio a la misma, Lutero reivindicó las dos especies al pueblo y tamentó que su celebración en latîn la hiciera inasequible. El ministro no re. novaba el sacrificio de la cruz, sino conmemoraba la promesa de perdón de los pecados, "promesa confirma. da por la muerte del Hijo de Dios... Si es promesa, no llegamos a ella por ninguna obra, por nıngün esfuerzo ni mérito, sino solamente por la fe (sola fides), porque donde está la palabra de Dios que promete, ahi se hace necesaria la fe que constituye el princi. pio de nuestra salvación." 36 El cautiverio que Roma impuso a este sacramento consistió en hacerlo un medio para negociar con misas votivas, encomendadas $y$ sufragios. Lutero fue especialmente duro contra el orden como sacramento (a pesar de que aceptó el rito eclesiástico para intro. ducir a los ministros en la comunidad): "El sacramento del Orden fue y cont $j$ núa siendo una maquinación bellisima para consolidar todas las monstruosidades que se han cometido hasta el presente y que aún se cometen en la Iglesia. Aquí desaparece la fraternidad cristiana, aquí los pastores se transforman en lobos, los siervos en ti. ranos, los eclesiásticos en más que mundanos... Los clérigos no sólo cre. en que ellos son más que los laicos cristianos, ungidos también por el Espíritu Santo, sino que llegan a considerar a éstos como perros indignos de ser ellumerados juntamente con ellos en la Iglesia." 37

La libertad del hombre cristiano es uno de los más bellos escritos de la tradición cristiana que Lutero, junto con una carta, envió al Papa León $X$.
Todo se articuló en dos proposi. ciones: "El cristiano es un hombre libre, señor de todas las cosas y a na. die sometido. El cristiano es un siervo obediente a todas las cosas y someti. do a lodos." El libro es una apología de la liberación interior: el hombre de fe se siente liberado de toda preocupación por su salvación. por la obser. vancia de preceptos y otros imperal. vos, porque sabe que la salvación es ofrecida gratuitamente por Dios. En función de este don está con las manos, los ojos y el corazón libres para trabajar en favor de sus hermanos por puro amor a ellos.38 La última proposición de su libro resume esta pers. pectiva: "El hombre cristiano no vive en si mismo sino en Cristo y en su prö. jimo: en Cristo por la fe, en el prójimo por el amor... Esta es la verdadera y espiritual libertad cristiana, que libera el corazón de todos los pecados, leyes y mandamientos, libertad que su. pera cualquier otra libertad, como el cielo supera a la tierra."

En el De servo arbitrio (de 1525 contra el De libero arbitrio de Erasmo) muestra que la libertad humana no puede afirmarse frente a Dios; su función consiste en acoger la acción salvífica de Dios; por si misma, la voluntad humana no puede, no liega a conseguir y mantener su relación con Dios, ${ }^{39}$ ésta proviene de la libre inicialiva de la misericordia divina. Pero en las cosas de la vida, en el mundo, ahi se ejerce la determinación humana y una vez agraciada, puede libremen. te colaborar con Dios en la construcción de su Reino. ${ }^{40}$

Para concluir esta parte debemos reconocer que, a pesar de los tremen. dos excesos verbales, juicios parciales y a veces erróneos, Lutero significa la presencia de la profecía autén- 
tica, llamando a conversión y reforma a toda la Iglesia. Ha sabido poner el evangelio y la cruz como marcos de referencia frontales para liberar a la Iglesia de todo tipo de abusos del po. der sagrado y de manipulación de las doctrinas al servicio del dominium mundi. No se puede negar un aura de libertad que permea los principales textos de Lutero y que se ha transfor. mado en fermento de liberación al in. terior del corpus christianorum. Sabemos que Lutero jamás pretendió crear una confesión cristiana paralela. Esto fue obra de los príncipes alema. nes a partir de la alianza de Torgau (1526, para hacer frente a una liga de principes catoolicos), sellada definitiva. mente en marzo de 1531 por la liga de Smalkalda. Cuando se firmó la paz de Augsburgo en 1555 ya encontra. mos la Alemania dividida entre lutera. nismo y catolicismo romano bajo el principio Cojus regio huius religio.

\section{b) La apropiación del espiritu protestante por los nuevos señores}

La actuación de Lutero fue liberadora dentro del campo religioso. La incidencia en la política no siguió la misma lógica. La Iglesia romanocatölica perdió el monopolio religioso y pasó a reubicarse dentro de un campo religioso dividido; su influen. cia social se hizo menor y tuvo que enfrentar la competencia, en lo confesional y también en lo político, de los principes que se unieron al luteranis. mo (gran parte de las regiones nördi. cas). Lutero mismo no estuvo en condiciones de controlar el movimiento que desencadenó. Ni siquiera tuvo conciencia de su incidencia sociopolítica; ni puede pedirsele porque eso transciende los límites de la "con- ciencia posible" de aquel entonces. Asi lo expresaba claramente Lutero: "Mi evangelio no tiene nada que ver con las cosas de este mundo. Es una cosa muy distinta que atañe única. mente a las almas y no es de mi competencia dar solución y expedición a los negocios temporales; para esto es. tán los que tienen tal vocación: el em. perador, los principes y las autorida. des. Y la fuente de donde deben extraer su sabiduría, no es el Evange. lio, sino la razón, la costumbre y la equidad. ${ }^{41}$

La falta de una articulación cons. ciente se hizo patente al estallar la guerra de los campesinos capitanea. dos por el predicador Thomas Müntzer (1489-1525). ${ }^{42}$ La insurrección hay que insertarla dentro de un movimiento mayor, muy anterior a la Reforma. La situación de los campesinos a prin. cipio del siglo XVI era bastante buena. ${ }^{43}$ lo que los movió fue la reivindicación de măs derechos fundamentales en el campo sociopolítico, como aparece en el documento de los Doce articulos. Por ello se unieron a su movimiento no solamente pequeños señores, sino abades, príncipes y obispos (Fulda, Bam. berg, Speyer). ${ }^{44}$ Obligado a tomar posición, Lutero escribió en abril de 1525 una Exhortación a la paz. A los señores les dice claramente: "No son los campesinos los que se sublevan contra vosotros, sino Dios mismo," y a los rebeldes: "Quien usa la espada morira por la espada; aunque los príncipes sean malvados $e$ injustos, nada os autoriza a rebelaros contra ellos." Lutero no fue, pues un revolu. cionario a nivel político. 45 Fue fun. damentalmente respetuoso del poder secular, porque vio en él instancias instituidas por Dios que había que 
obedecer. Explicítamente, en 1521. en Wartburg, sc pronunció contra la rebelión y la sedición: "Yo me opon. go y quiero oponerme siempre a los que usan la violencia, por más justa que sea, porque la rebelión no se satisface sino con la efusión de la sangre inocente. ${ }^{.46}$

Con razón, Jean Delumeau concluye: "La rebelión de los campe. sinos puso en evidencia la incompe. tencia política del reformador. Especialmente, le hizo perder la fe en el pueblo organizado en comunidades. Desde aquel momento tendió a pedir a los príncipes la institución del culto reformado. Al Lutero de la "libertad cristiana" sucedió el Lutero de "la Iglesia del Estado" (Landeskirche). ${ }^{47}$

Para comprender la incidencia de lo religioso sobre lo socio-político hay que preguntarse por los aliados que el movimiento religioso genera. En el caso de Lutero podemos decir con seguridad, que más que el pueblo pobre, los campesinos y siervos de la gleba, fueron los príncipes, los huma. nistas, los artistas (Dürer, Granach y Holbein), los burgueses urbanos, sus verdaderos aliados. El proyecto histórico incrustado en sus prăcticas no va en la línea de una liberación, sino en la de acumulación de riquezas y privile. gios. Max Weber ha mostrado la con. naturalidad existente entre el protestantismo y el capitalismo. ${ }^{48}$ La vivencia de la fe en moldes protestantes es funcional para el establecimiento y expansión del modo de producción ca. pitalista. "En la medida en que el mundo occidental se rige por la lógica del capitalismo, podemos concluir que el protestantismo se siente en este mundo como en su casa, mientras que el catolicismo se encuentra como exilado. La ideología protestante unifi- ca la libertad del individuo, la de. mocracia liberal y el progreso econó. mico come expresión del espiritu protestante. En resumen: el mundo moderno es fruto del protestantis. mo." 49

La asociación histórica del lutera. nismo con los principes y la burguesía victoriosa hizo que el protestantismo histórico incorporara y asi legitimara los intereses y los ideales sociales de esta clase.

Paul Tillich vio muy bien el gran re. to que le planteaba al protestantismo moderno el proletariado y su causa. Dice que "desde muchos puntos de vista pareciera que el protestantismo y la situación obrera nada tienen que ver la una con la otra... La situación proletaria, en la medida en que repre. senta el destino de las masas, es refractaria a un protestantismo que, en su mensaje, confronta la personalidad individual con la necesidad de hacer una decisión religiosa y entrega dicha personalidad a si misma en la esfera social y política, considerando que las fuerzas que dominan la sociedad fueron ordenadas por Dios. "50 El famoso individualismo protestante. se siente impotente y mudo frente a estructuras de injusticia. En la medida en que no reflexiona evangélicamente sobre este desafio, corre el riesgo de encubrir los conflicios que agobian a los pobres y, asi, de no aportar una colaboración a la tarea mesiánica de liberación de los condenados de la tierra.

Volviendo a la cuestión que plan. teábamos con respecto al protestantismo latincamericano, debemos decir que se confirman las sospechas segün las cuales no hay una articulación a un nivel social, entre protestantismo y liberación de los pobres. Esta articu. 
lación debe ser construida a partir de algunas intuiciones de Lutero y especialmente de su espiritu francamente liberador al interior de la Iglesia.

\section{El evangelio protestante como factor de liberación de los oprimidos}

En primer lugar, hay que captar con claridad que la situación actual es profundamente distinta a la del tiem. po de Lutero. En su tiempo, la Iglesia jugaba el papel central en la reproducción del sistema social, de tal forma que los cambios introducidos por Lutero en el campo religioso pudieron repercutir inmediatamente sobre lo social. Hoy la religión juega un papel subsidiario. En nuestras sociedades capitalistas, a pesar de ser periféricas y elitistas, la actividad económica constituye la actividad central y organiza hegemónicamente todas las demás, produciendo una inmensa marginación del pueblo empobrecido. Esto significa que la posible liberación no ocurre sólo con transformaciones al interior del campo religioso sin una explícita articulación con los demás campos, más determinantes y dominantes en nuestra coyuntura. A partir de lo socio político y en permanente conexión con èl, el factor religioso puede mostrarse liberador.

Para terminar queremos señalar al. gunos puntos del evangelismo protes. tante rico en contenido liberador.

\section{a) El principio protestante}

Paul Tillich ha acuñado esta expre. sión, ${ }^{11}$ con ella quería expresar la in. turción fontal de Lutero. El se sublevó, en nombre del evangelio, contra la prepotencia del poder sagrado. contra lo condicionado que usurpó la condición de lo incondicionado. contra lo histörico que se presentaba como divino. El espíritu protestante desenmascara los idolos religiosos y políticos y rechaza simplemente legitimar el status quo. Todo tiene que entrar en un proceso de conversión y cambio, es decir, liberarse de todo tipo de opresiones para ensanchar el espacio de la libertad para Dios y para la acción libre del ser humano. El principio protestante ayudará a los propios protestantes a liberarse de su rigorismo burgués para apoyarse en el radicalismo evangélico, como lo hizo Lutero.

\section{b) Recuperaclón del poten- cial liberador del evangelio}

El significado más grande de Lutero fue su profunda vinculación bíblica y evangélica. En un tiempo en que el evangelio estaba cautivo de las élites ilustradas y clericales, Lutero lo rescató como viva vox y lo puso en las manos del pueblo. En América Latina, el evangelio leido y meditado en centenares de círculos biblicos y millares de comunidades cristianas de base es la gran fuente de contestación profética contra el sistema de explotación y de compromiso liberador. El potencial liberador de las Escrituras emerge cuando estas son leidas a la luz de los interrogantes que vienen de la con. flictividad social y del grito del oprimido. Este intercambio entre Palabra de Dios y palabra de la vida empobrecida y humillada recupera la actualidad permanente de la revelación y de la acción salvadora de Dios, instaurando su Reino contra las artimañas del anti-Reino. 


\section{c) La fe que se robustece por las obras de liberación}

Lutero nos ayuda a todos a enten. der que la liberación arranca del don de Dios, quien, antes de cualquier ac. ción histórica de parte de los nombres, toma la iniciativa. Esta con. ciencia no exime a las personas de su compromiso de lucha. Al revés, las mueve con mayor libertad a lanzarse a producir buenas obras, que son buenas en la medida en que liberan al prójimo. En este sentido, Lutero pone en contraste la fides abstracta vel absoluta (fuera de las obras buenas) con la fides concreta, composita seu incarnata (activa en las obras buenas) ${ }^{52}$ En función de esto, Lutero puede hablar de Cristo actuosissimus en sus miembros, quienes han asimila. do las actitudes de Jesucristo y asi viven una vida convertida y liberada 53 En una expresión concreta, recalca que la fe se robustece por medio de las obras hechas a partir del don y dela misericordia. ${ }^{54}$ Estas obras hoy en día no pueden reducirse al ämbito de la subjetividad, sino incidir sobre las estructuras de la sociedad. Para garan. tizar eficacia a la acción que nace de la fe debe preceder un análisis de los mecanismos productores de opre. sión y se deben definir los pasos concretos que promueven la libera. ción. En esto, tanto católicos como protestantes, debemos aprender $y$ hacernos discípulos de una prắctiça leológıca distınta que sepa, sin servi. lismo ni paralelismo, articular el dis. curso de la fe evangélica con el dis. curso social. Desde dentro de esta conexión surge la potencia liberadora de la fe cristiana.

Finalmente, hacemos nuestras las palabras de la Comisión Mixta
Catôlica-Luterana Internacional (mayo de 1983): "Consideramos conjuntamente a Lutero como lesligo del Evan gelio, maestro de la fe y voz que llama a la renovacón espiritual." 55 Para nosolros en América Latina el evangelio necesita ser vivido de forma li. beradora; la fe, como productora de un compromiso con los más necesita. dos desde la experiencia de la miseri. cordia primera de Dios, y la renova. clón espiritual, como una mistica que une fe y política y construye la comunidad desde abajo, desde los más hu. mildes para que sea verdaderamente la comunidad mesiánica que prolonga la misión redentora y liberadora del Mesias lleno del Espiritu, Jesucristo.

\section{NOTAS}

1. Para nuestra lectura son importantes: $W$. Becker. Reformation und Revolution, Munster." 1983; R. Wonlfell ( $\mathrm{Hg}$.), Reformation oder frühbürgerliche Revolution, Munchen, 1972; J. Delumeau, La reformo, Barcelona. 1977; Las causas de la Reforma la explir ación marrisra. 181, 191. OH Resell. Hinfürung zu Luther, Mainz, 1983. esp. 304. 307: P Chaunu, Eglise, culture et société. Essais sur Réforme et Contre-Reforme 1517-1620, Paris, 1981

2 . Cr. R. Oliveros, Liberación y Teología. Génesis y crecimiento de una reflexión 1966-1977, Lima, 1977; A.g Rubio Teología da libertacso: política ou profetismo, Sao Paulo, 1977, L. Goff CI. Boff, Libertad y Liberación, Salamanca, 1982. 2955

3. CI. G Gutiérrez, Teologla de la Liberación, $\{, \ldots, 1,1,7\} 116, \ldots, ?, 2 \%$

1 (1 V.r.w. Historia da teología na América Latina, 5 Pin:l: 1091130 i/14

5 P. Negre. Sociologia do terceiro mundo, Petrópolis. 1977. en donde se hace un balance de las varias corrientes de in terpretación del subdesarrollo.

o. Cl. L.Both, La fe en la periteria del mundo. El caminar de la Iglesia con los oprimidos, Santarider. 1981

7. Varios, La sangre por el pueblo. Nuevos mártires de A. Latina finstituro Hisiogres? Centroamericano), Peliobolis, 1983. 
8. C.F. O Maduro, Religiao e luta de classes, Pelrópohs, 1981. 69-112; P. Bourdieu.

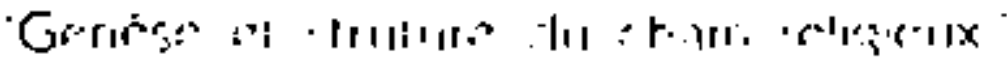
en Revue Francaise de Sociologie 12(1971), 295-334

9. P. Richard, "Teologia da libertacao latino. americana." en A Igreja latinoamericana entre o temor $e$ a esperan. ca, Soo Paulo, 1982, 13.34

$10 \mathrm{Cl}$. R. Vidales, "El sujeto histórico de la reologia de la liberación." en Taller de teología 2 (México 1978) . 9.19)

11. Cf Boff, Teología y práctica. La teologia de lo politico y sus mediaciones, Sala 7anc a. 198I

12. Cf Varios, Protestantismo y liberalismo en América Latina, San José de Cosıa Rica (DEI), 1983; E. Willems, Followers of the New Faith: Culture Change and the Rise of Protestantism in Brazil and Chile, Nashville, 1967: W.R. Reed, V.M. Mon. terroso, H.A.Johnson. Avance evangêlico en América Latina, Dallas, 1970; Ch.L. D' Epınay, El rehugio de las masas: estudio sociologico del protestantis mo chileno Santıao. 1968 W A César. Por una sociologia do protestantismo brasileriro, Petrópolis, 1973.

13. Religión y fe en América Latina, México. 1961, 10.

14. Cl. J.M. Bonıno, "Historia y misıón. Los es. tudios históricos del cristianismo en Amé. rica Latina con relerencia a la búsqueda de liberación." en Protestantismo y liberalismo en América Latina, op. clt., 25

15. Cf. R. Alves Protestantismo e repressao, Sao Paulo, 1979, 38-42: "O protestantismo como vanguarda de liberdade e da modernidade "Alves expresa asi la autoconcien. cia de un fiel protestante "Se preguntar. mos a hıstórı: de que lado estä́s? Qual ह́ o teu destino? Ela responderá: $O$ catolicis. mo è o passado de onde venho O protes tantısmo e o fulurc para onde camınho" (p 38 )

16. Citado por C. Alvarez, "Del prolestantis. mo liberal al protesiantisrio liberacior en Protestantismo y liberalismo en America Latina, op cit., 49

17. Cl. El laberinto de la soledad, Méxuco. $1974,99$.

18. Historia y misión, op. cit., 31 .

19. Protestantismo, cultura y sociedad, B Alres, 1979, 110-127.

20. "Función ideológica y posibulıdades ulópicas del protestantismo latinoamericano." en De la Iglesia a la sociedad, Tierra
Nueva (Uruguay). 1971, 21.

21. Para lodá esta cuestión véase la obra fun. damental de $O$ maduro. Religiao e luta de classes, Petrópolis, 1981; Cl. lambién $M$ Godelier, "Marxisme, anthoropologie et relıgron, "en Epistemologie et marxisme, Paris, 1952, 209-265: H. Portelt, Gramsci y la cuestion religiosa, Barcelona, 1977. 58.64

22 Etudes sur la Reforme Francaise, Paris 1909.83

23 Obra clasica sigue siendic; lodiavia ba de J Lorrz. "W/ie es zur Spallung karn Von de Ursochen der Relormation." en Die Reformation als religiöses Anliegen heute, Trer, 1948. 15-105, Die Reformation und Deutschland, vol. I. I il)uigo. 1949. 320. $\mathrm{H}$. Lowe, C.J. Roepke $(\mathrm{Hg})$. Luther und die Folgen, Munchen, 1983.

24. Vorlesungen über die Geschichte der Philosophie III (Suhrkamp, Werke 20). Frankfurt, 1971, 49, 5051.

25. C. O. Maduro, "A relıgıa no regıme semı. reudal da Colónıa," en Religiao e luta de classes, op. cit., $87 \mathrm{~m}$

26. Cf. J. Delumeau, La reforma, op. cit., 32.

27. Cl. O.H. Pesch. Theologie der Rechtfertigung bei Martin Luther und Thomas von Aquin. Versuch eines systematisch-theologiscinen Dialogs, Maınz, 1967; Id. Hinführung zu Luther, op. cit. 264-271.

28 Para una exposición de este concepto de

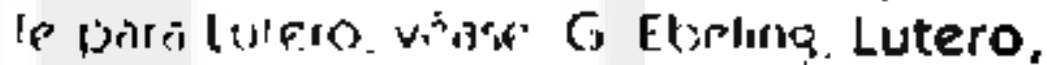
un volto nuovo, Brescia, 1970, 145.15

29. W/A IV3,28 55: $56,3,135,4,11 ; 172,8$; 268,455.

30. Cf. Mestre Eckhart: a mistica de ser e de nao ser (org. L. Boff), Perrópolis, 1983. 104.105:111.114

31. Citado por J. Delumeau, La Reforma, op. cit., 35.

32 Segun la edicion de Willietm Goldniann Verlag, Munchen, 1967, 38.

33. Id. ibd. $\%$

34 Utilizarros la traduccion viasileńa de Eorlora Sinodat. Sao Leopoldo. 1982. 14

35. WA VI,572,11:550,9,25.

36 Do cativeiro babilönico da Igreja, Så Le.opo! do $1982.36 \cdot 37$

37. Id., 126-127

38 Para toda esta cuestión: W. Maurer. Von der Freiheit eines Christenmenschen, Zwei Untersuchungen zu Luthers Reformationsschriften 1520, 1521, Goltigen, 1949.

39 Para lutero, la comprensión delendida 
por Erasmo de Rotterdam acerca del libre albedrio llevaba a una excesiva autonomía frente a Dios Asi definia Erasmo el liberum arbitrium: "la fuerza de la voluntad humana mediante la cual se puede dirigır a aquellas cosas que conducen a la salva. ción o se alejan de ella, Diatrlba seu collatio de libero arbitrio, I b. 10.7-10

40. Para esto WA XVIII, 695,29; 754,1-17; $\mathrm{M}$. Seils, Der Gedanke vom Zusammenwirken Gottes und des Menschen in Luthers Theologie, Gulerslot. 1962

41 WA XVIII. 321

42. C.F. M.M. Smırın, Die Volksreformation des Thomas Müntzer und der grosse Bauernkrieg, Berlin, 1056. P Alrhdus, Luthers Haltung im Bawernkrieg, Basel I. 1953.

43. J. Lortz, Die Reformation in Deutschland I, op. cit. 322.

44. Id., 324.

45. G. Casalis, Luther et I Eglise Confessente, Paris, 1993, 82.

46. Citado por G. Casalis, op. cit., 89. Lutero era amigo de jefes de la represión campe. sina como Felipe de Hessen y les dijo: "Hay que estrangularlos. Hay que matar al perro enloquecido que se lanza contra tı: sı no, él te matará:" de su escrito Contra las cuadrillas ladronas y asesinas de los campesinos. Esta posición de Lutero ja. más será olvideda por los oprimidos que no tienen claridad en la articulación de la religión en una sociedad de clases, religión que puede ser cooplada en función de los intereses del grupo hegemónico. En su Comentario al Magnificat Lutero re. vela una interpretación espiritualisla al re. ferirse a los ricos y poderosos y a los pobres y humillados Asī. dice "Los hambrientos no son los que poco o nada tienen para comer, sino aquellos que, vo- luntariamente, aceptan privaciones, prin cipalmente si a esto son movidos nor otros, por amor a Dios o a la verdad " $y$ da esias razones para no considerar las i terencias rico pobre. "Dios no: (17ph in in hombres por sus apariencias Pocolle ini. porta que sean ricos o pobres. que oris. pen posiciones de ralevanc:a 's aue 'er: gan una situación social de menor provec. ción. Lo que El mira es el espiritu que lus anima En la sociedad siempre exisinill: prualegiados y desheredados Les prill: ros no jeben apequrse a tets verilidals id. que disfrutarl y los segundos deben man. ipnerse serenos," $M$ lutero. O Magnifi. cat, Petrópolis, 1968,91.92; cf también. en 82.87. el comentario espiritualizante del texto "derriba del trono a los poder sos y exalta a los humildes."

47. La Reforma, op. cit., 4h

48. La ética protestante y el espiritu del capitalismo, Barcelona, 1969

49. R. Alves, Protestantismo e represseo, op. cit., 42, refiriéndose a la autoconcie.n. cia de los protestantes.

50. P. Tilich, The Protestan Era, Chicago, 1962, 161.

51. Id, 163 .

52. Rapsodia de loco justificationis (1530): W/A $\times \times \times, 2,659,13.21$; P.Manns, "Fides absolutafides incarnata. Zur Rechtlertigung. slehre Luthers im Grossen Galater. Komentar," en Reformata Reformanda (Fest. H. Jedin, 1), Münster, 1965, 265.312.

53. WA I, 364,23,28; Cf. J. Wicks, "Il cuore della teología di Lutero, en. Ressegna di Teologia, 24 (1983) 110-125; 219-237. "Fe. de e giustificazıone in Lutero "

54. WA $\times \times \times, 2,659$.

55. Martinho Lutero lestemunha de jesus

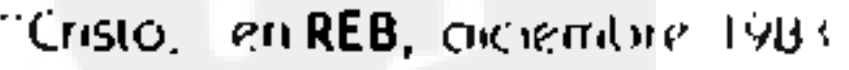

